\title{
E-Learning Management System Based on Reality Technology with AI
}

\author{
Kongkiat Hirankerd and Nattapakal Kittisunthonphisarn
}

\begin{abstract}
In the present time, the skill training for work is important to the industry and education. Practicing various skills are necessary to use technology to apply for many reasons: Safety reasons for resources, locations, time and limitations. AR VR MR or XR Technologies are increasingly used worldwide, because the equipment materials are more ready but the present learning management system Different from the skill training management system. The storage and using in video format that have been used for more than a decade. Therefore, this research is developed a system that will manage learning, practice skills with AR VR MR Technologies as well as use AI to be used in the management system as well.
\end{abstract}

Index Terms-Augmented reality, virtual reality, artificial intelligent, e-learning system.

\section{INTRODUCTION}

The present time many field of education need to provide skill training to student or learner Equivalent to knowledge and understanding. Skills are important in many aspects of work. Therefore, the development of e-learning systems that are able to support skills training is essential in today's education system. The industry needs workers with work skills, which requires training with tools and the environment Rather than memorizing and watching videos. [1] For example Bring 10 students who are not swimming. Bring all students to watch the video, teach swimming until they understand all. Then bring all the students to jump into the pool. The result is that all drowning cannot survive.

Skill training through AR VR MR or XR Technologies can be used to practice skills in: teamwork, time management, mindful control, body control for imagination, visualization for practical work [2]. Training of work skills with technology for examples through in computer game which playing the game is actually a skill training style if there is a change of content, information, situations, and patterns for linked to work and reality. The technology can divide with tools and situation.

1) Using technology to practice virtual tools such as Virtual surgery, Virtual robot control. [3] When it comes time for the learner to use real tools, the learner can use it fluently and correctly.

2) Using technology to training in virtual situations such as firefighting training, virtual combat, virtual factory, and virtual dangerous area. [4] By the time the learner is in a

Manuscript received September 9, 2019; revised March 1, 2020. This work was supported in part by Rajamangala University of Technology Rattanakosin, NakhonPrathom, Thailand.

The authors are with the Department of Digital Media Design, Rajamangala University of Technology Rattanakosin, NakhonPrathom, Thailand (e-mail: kongkiat.hir@rmutr.ac.th, Nattapakal.kit@rmutr.ac.th). situation that is similar to the situation and environment that the learners have trained in, they can make their consciousness and practice correctly.

\section{RELATED WORKS}

\section{A. Augmented Reality}

AR technology can bring things that do not appear on the real world through mobile devices [5] (mobile phone and tablet) with the background as a real environment, allowing users to feel the real existence of those virtual objects as well as users can interact with those virtual objects.

\section{B. Virtual Reality}

VR technology can bring users to virtual locations with change the environment from the original address to another. The environment may be real place or place created by computer graphics, when user look through the VR glasses device. [6] Everything in virtual environment can be controlled via a pointer or a joy stick, which has to be careful of user moving to hit object around in the real environment.

\section{Mixed Reality}

MR or XR technology has the characteristics of a combination of AR technology and VR technology, because users will see the image like AR, but the using of the device will be worn and controlled like VR. [7] The problem of the user moving to hit objects around in the real environment will disappear.

\section{E-Learning System}

The e-Learning system is a system that consists of subsections for the purpose of promoting learning. The systems have different content, tools or forms to create learning in appropriate context. [8] The learning design was designed with internal management of content, processes and learners to learn as well as analyzing and testing learners. Characteristics of the use of e-learning systems with artificial intelligence in management have characteristics that are managed in two ways: managing the content of learning and analyzing learners.

\section{E. Artificial Intelligent}

Artificial intelligence (AI) is a simulation of human intelligence by machines, especially computer systems. These processes include learning (Acquisition of data and rules for data usage) Reasoning (using rules to get an approximate conclusion or exact conclusion) and self-correction AI-specific applications, including expert systems, speech recognition and machine vision. [9]-[11] The artificial intelligent systems were used in the e-learning 
system for link and analyze learners and the content of information in the database.

\section{METHODS}

The researcher team has compiled information of e-learning systems in all aspects. In the e-learning system standard to identify patterns and analyze the internal components of the e-learning system. The team found that the internal elements were mostly video. [12]-[15] (Images and sounds). The contents are larger than image files and characters. The research process are data collection, need for the use of e-learning systems and current information that requires training in work skills or learning skills, makes the researcher design the e-learning system process. [16] The important skill training with AR VR MR or XR technology is used to practice or learn the skills that are necessary for industrial development in many aspects. (as show in the Fig. $1)$.

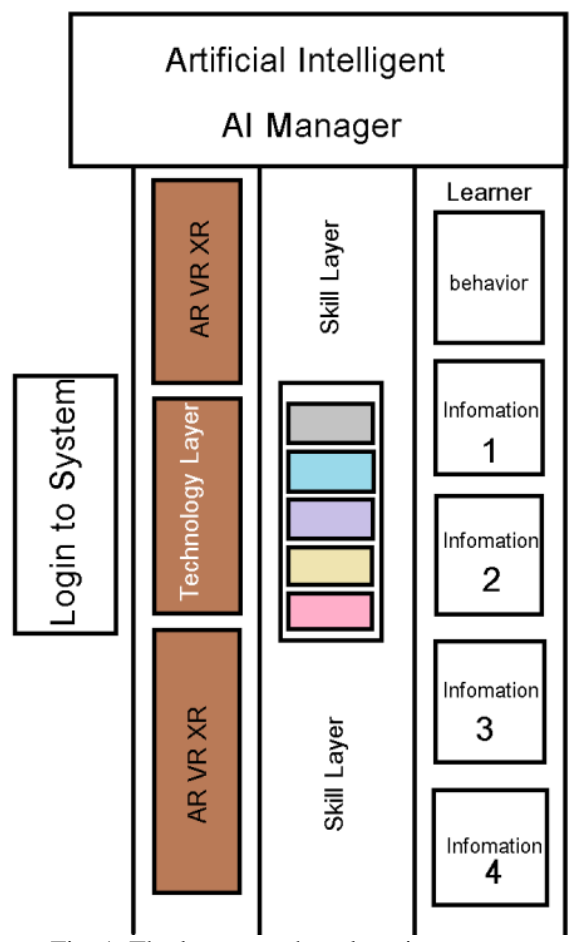

Fig. 1. The layers on the e-learning system.

TABLE I: TYPE OF CONTENT AND TECHNOLOGY

\begin{tabular}{lcccc}
\hline \hline Skill / Technology & AR & VR & 360Video & XR \\
\hline Engineering & $/$ & $/$ & - & $/$ \\
\hline Sport & $/$ & $/$ & $/$ & $/$ \\
\hline Industry/Experience & $/$ & $/$ & - & $/$ \\
\hline Medical & $/$ & $/$ & $/$ & $/$ \\
\hline Education & $/$ & $/$ & $/$ & $/$ \\
\hline \hline
\end{tabular}

From the process Table I within the developed e-learning system, it is divided into 2 types: Classification according to the type of AR VR MR or XR technology skill training according to the technology before. After that, it will be divided according to the skills of job training such as sports learning, medical, engineering etc.

Technology Layer: This system has divided for 3 groups of technology that offer to learner. AR or Augmented Reality Application was packed to an android application (apk file) separated with each content for installing to any android device. The system will check hardware and android version of installing device before offer AR Application to install. VR Virtual Reality Application has 2 types, the first type is VR 3D animation and the second type is VR 360 environment Video or picture. The VR 3D animation were made from 3D Software such as Maya, 3D MAX, Unity3D and VR 360 environment Video or picture were captured with 360 Full HD camera. The 3D animation was showed on android application after version 5.1 and the VR 360 Video or picture was showed via internet browser. MR or XR or Mixed Reality application that run on android system version 7.0 at less, these applications look like AR Application for show 3D animation on the real-world background, but the learners have to wear VR headset or VR glasses and control with pointer or joystick or controller.

Skill Layer: The researcher made questionnaire 400 sets for ask to public people, the questions focus to how many groups for skill that relate with AR VR and XR or MR. The information of the data from 400 papers of questionnaire are 5 groups. The groups of skill layer are sports, medical, engineering, experience, and education.

Example of each groups: Sport groups are boxing, ride bicycle, dancing (show in the Fig. 2). Medical groups are human body model and body work process (show in the Fig. 5). Engineering groups are engine work process and mechanical components (show in the Fig. 3). Industry /Experience groups are field trips, tourism, and game (show in the Fig. 4). Education groups are Language learning, Science, and Mathematics (show in the Fig. 7).

Learner Behavior Layer: The researchers are trying to focus on the elements of learning. The learner must put basic information such as name, birth date, academic information, life style etc. This layer will collect point from learner with 2 types (rating with learner and system count from learner behavior).

TABLE II: NUMBER OF CONTENT SKILL VIA TECHNOLOGY

\begin{tabular}{|c|c|c|c|c|}
\hline Skill / Technology & $\mathrm{AR}$ & VR & 360Video & XR \\
\hline \multicolumn{5}{|l|}{ Sport } \\
\hline - Boxing & 3 & 3 & 0 & 4 \\
\hline - Ride Bicycle & 0 & 2 & 0 & 0 \\
\hline - Dancing & 5 & 4 & 6 & 1 \\
\hline \multicolumn{5}{|l|}{ Engineering } \\
\hline - $\quad$ Engine work process & 5 & 5 & 10 & 3 \\
\hline - Mechanical components & 9 & 5 & 10 & 3 \\
\hline \multicolumn{5}{|l|}{ Medical } \\
\hline - Human body model & 25 & 2 & 0 & 6 \\
\hline - Body work process & 12 & 5 & 0 & 9 \\
\hline \multicolumn{5}{|l|}{ Industry /Experience } \\
\hline - Field trips & 2 & 3 & 20 & 3 \\
\hline - Tourism & 0 & 2 & 39 & 0 \\
\hline - Game & 0 & 0 & 0 & 12 \\
\hline \multicolumn{5}{|l|}{ Education } \\
\hline - Language & 5 & 7 & 2 & 5 \\
\hline - Science & 5 & 3 & 2 & 2 \\
\hline - Mathematics & 10 & 3 & 2 & 3 \\
\hline
\end{tabular}

\section{EXPERIMENTS}

The researcher developed an e-learning system consisting of content that is practiced in various skills supported by 
Augmented Reality, Virtual Reality, and Mixed Reality technology. The system created by the researcher consists of a framework to increase the type of skills in order to make additional improvements and can be searched quickly and thoroughly.

The application will make the correct posture according to the rules of Muay Thai sports for the learner. (show in the Fig. 2) This will be shown in the 2020 Olympic Games in Japan.

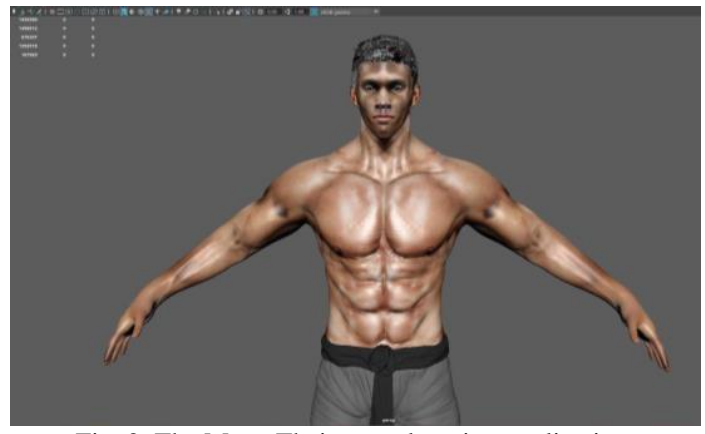

Fig. 2. The Muay Thai sports learning application.

Engineering skills training with AR 3D Animation, it shows the work of internal equipment for learners to understand the mechanical and physical functions of the device. Both physical and electrical understanding show to the learners, can adjust the functions to see the changes that occur immediately, as if using the device with absolutely no danger. In the Fig. 3 show application for Electricity Generating Authority of Thailand. (EGAT)

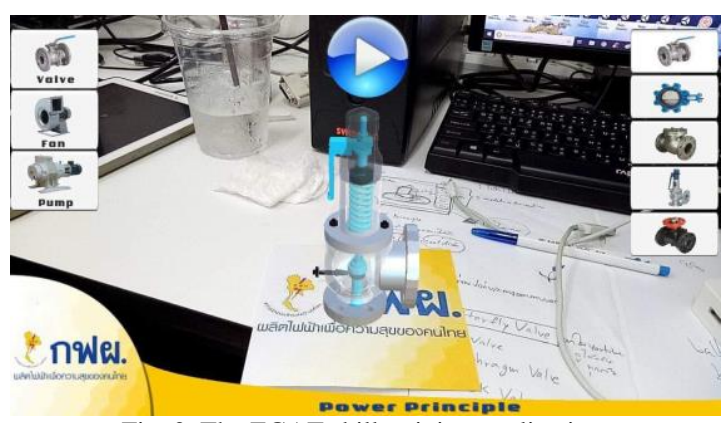

Fig. 3. The EGAT skill training application.

Virtual Field Trip (VFT) (show in the Fig. 4) bring the learner change location to the set location. In this research, this application was used for showing many danger zones in factory. The learner can participate with moving pointer.

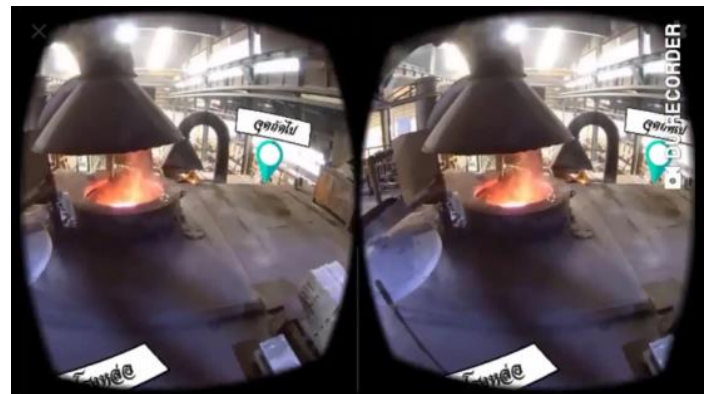

Fig. 4. The VFT skill training application.

The practice of medical skills consists of displaying various components in the organs in detail, as well as inside information (show in the Fig. 5). Learners can separate and combine parts that are components of the organ, so that the learning process is as accurate as practicing with real organs, but can see things that are latent, such as blood flow or nerve electrical current [17].

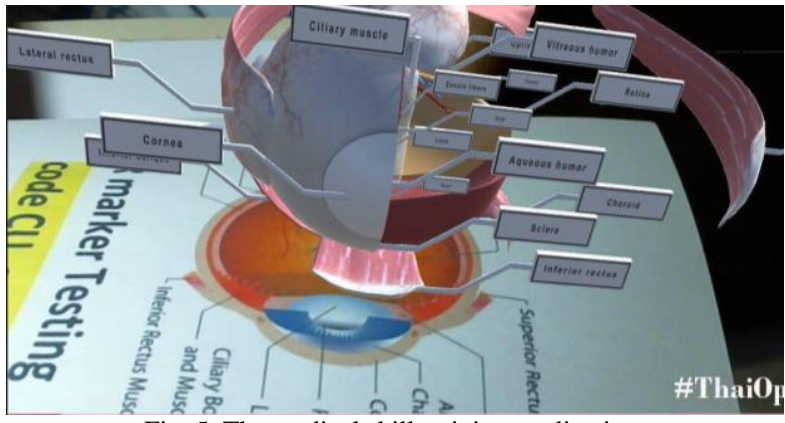

Fig. 5. The medical skill training application.

AR applications for training, control and command of industrial robots Due to the skills in controlling the order of industrial robots, it is highly desirable, but the industrial robot arm is very expensive. To be used for skills training, there are limitations on the number of robots per user learn. Development of AR robotic arms (show in Fig. 6) for replacement of real robots, it reduces to access restrictions for complete robot control skills training.

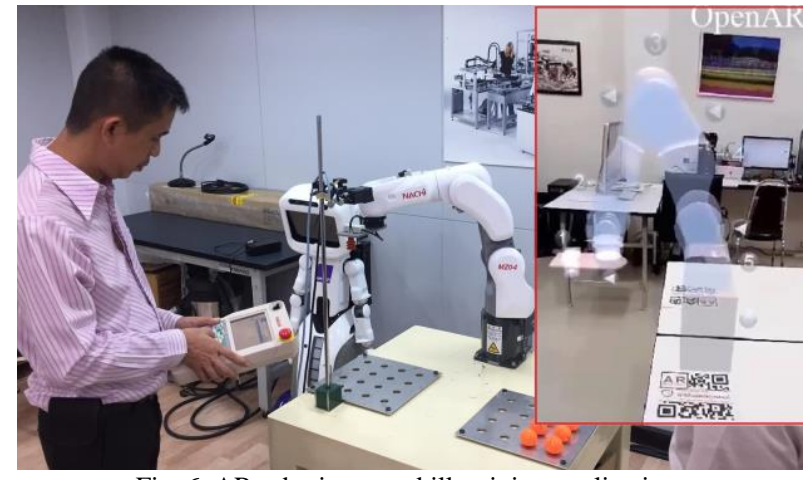

Fig. 6. AR robotic arms skill training application.

AR Application for teaching physics Nuclear, (show in the Fig. 7) due to the imagination of learning in some lessons, must understand the principles of physics which are difficult to imagine. Therefore, the simulation comes out in 3 dimensions and allows the learner to see the process in each step up, but in real step, unable to expand for details.

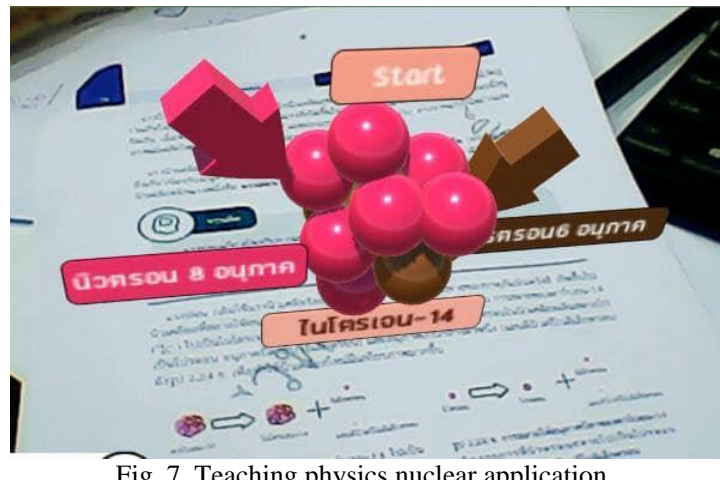

Development of VR for fire fighting skills, that the learner can decide and choose the type of fire extinguisher tank correctly according to the type of fire base (show in the Fig. 8 ). The Implementing firefighting missions practiced learner skills by defining time, problems and conditions. [18] Multi-places challenge the learners with design from the real 
situation, the layout of fire-places (show in the Fig. 9). The researcher developed VR places in 3D (show in the Fig. 10), lighting, sound arrangement, conditions, and types of fire.

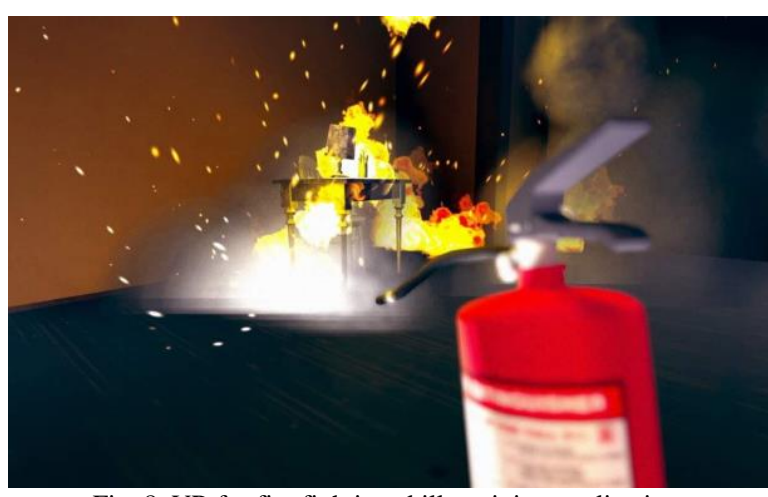

Fig. 8. VR for fire fighting skills training application.

The researcher designed of the shape of the place and the location of the fire. The learners must understand type and base of the fire, as well as the path that the learner must move to the exit. The challenge of learning is managing the fire correctly all points in that place with limited time.

Map 1 House

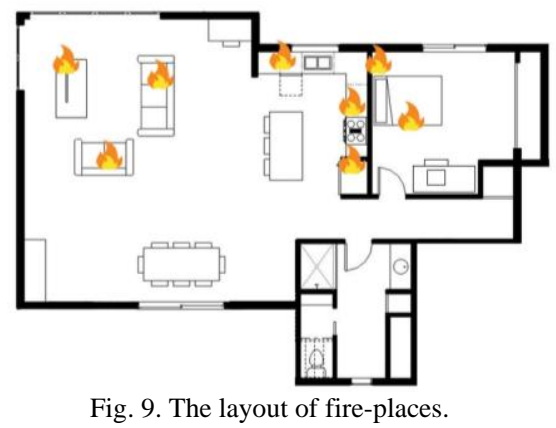

After the researcher has designed the 2D model, the next step is to create $3 \mathrm{D}$ and create the most realistic texture and detail in virtual environment. Determination of the location of the fire incident is defined in detail on the construction plan from the beginning with details of the type of combustion, such as fire, wood material, chemical or electrical. [19]

Materials and equipment Which is defined in the situation will be broken down by materials that are realistic, broken into powder, can be bent to increase the realism of use even more. Walkway design for learners to be able to walk in a virtual place in search and fire hydrant, as well as Avoid the obstacles that are in that situation.

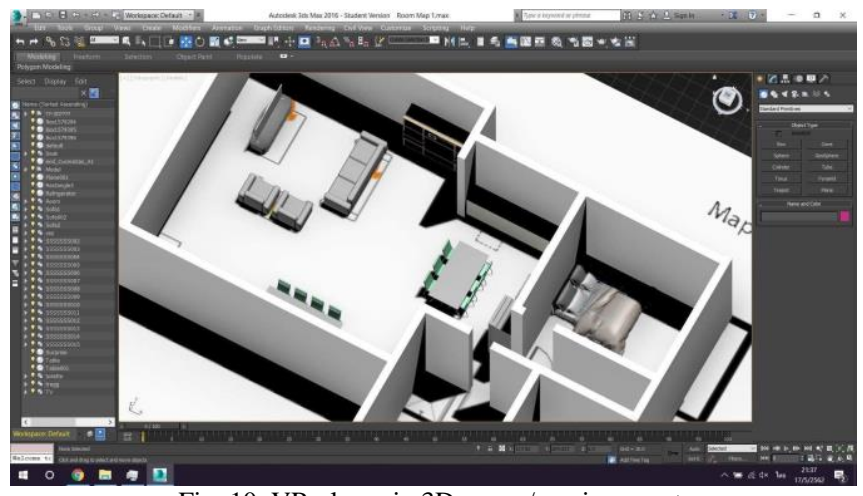

Fig. 10. VR places in 3D room / environment.

\section{FUTURE WORKS}

\section{A. VR Emergency Situations Simulator}

The researchers are developing VR in emergency situations (show in the Fig. 11 and Fig. 12) by inviting experts in crisis situations of famous car factories.

The information from the expert is collect types of emergency situations as well as procedures and processes to solve problems when that situation arises. Connection between Virtual Reality (VR) and Internet of things (IoT) so that the virtual situation can control the hardware to work together simultaneously. So that users feel like they are in an emergency.

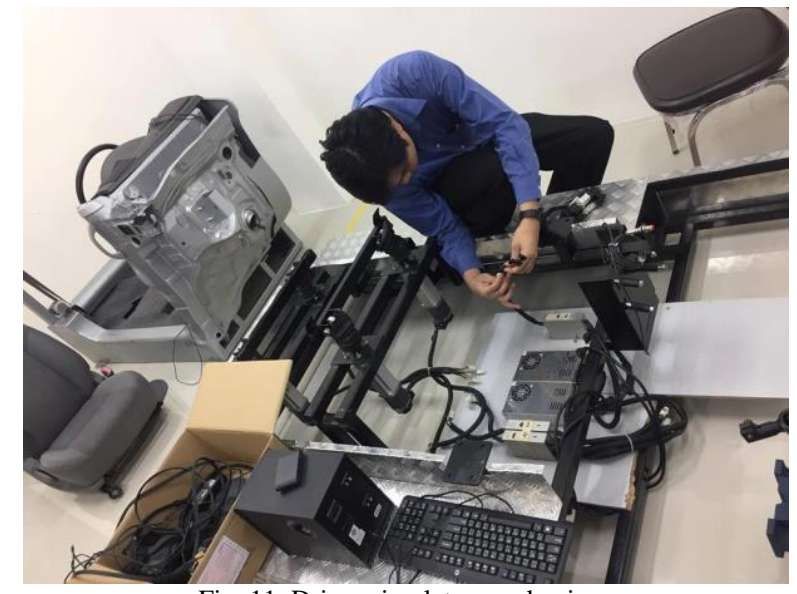

Fig. 11. Driver simulator mechanism.

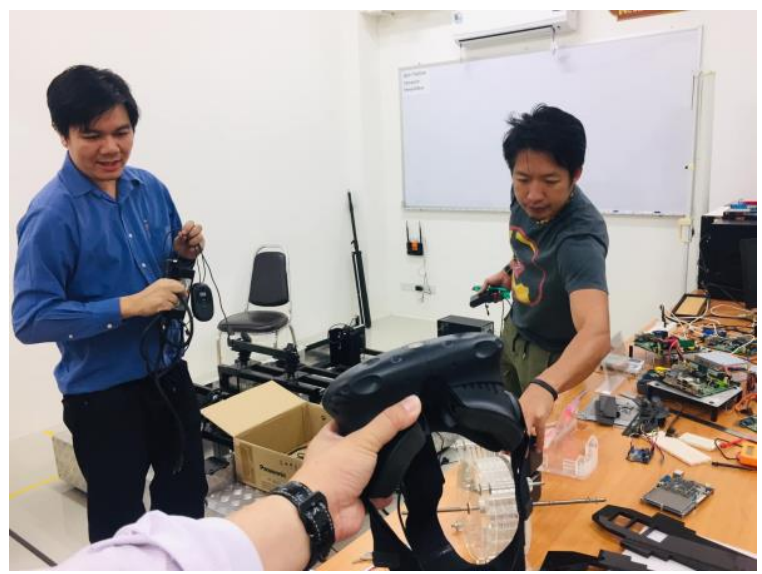

Fig. 12. VR headset for the learner.

\section{B. E-Learning for Working Skill}

The development of e-learning systems for skills training with AR VR and XR that allows the import of data from external skill content into the system. The system has to check the content appropriately before the learners in the system can use it. The system will offer relate content for the information of user automatically. [20]

Artificial Intelligent system is used to many industries, so e-Learning industry is using AI for teacher in e-Learning system (show in the Fig. 13). Virtual Learning Environment (VLE) [21] has many types of content inside such as Video, Text, Community, 3D animation. 


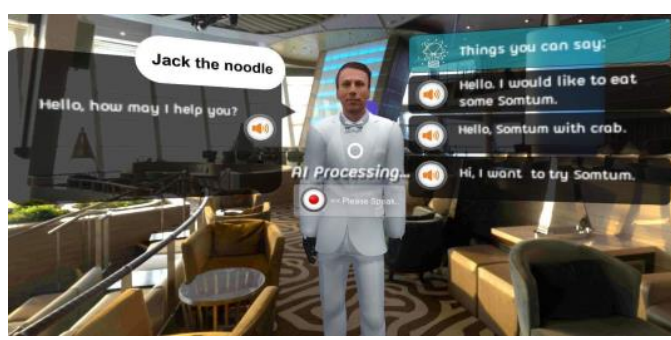

Fig. 13. VR learning environment with AI teacher.

\section{CONCLUSION}

Conclusion the development of e-learning system for skills training using AR VR XR technology can be divided into two types: First, consider the technology as the core of separation and the second type, consider the type of work that trains skills. The researcher has developed a system that can switch both types. The researchers are developing systems that can be connected and supported to a variety of hardware.

Learning process through effective electronic media must be an effective element and procedure. The researcher used the technology of AR VR and XR, that responded to the learning styles in each category of learning by which learners recorded the usage behavior of all media of the learner. Linking analysis between technology and electronic media usage patterns to practice skill is good information for develop reality media to efficiency.

\section{CONFLICT OF INTEREST}

The authors whose names in this paper immediately below certify that they have NO affiliations with or involvement in any organization or entity with any financial interest (such as honoraria; educational grants; participation in speakers' bureaus; membership, employment, consultancies, stock ownership, or other equity interest; and expert testimony or patent-licensing arrangements), or non-financial interest (such as personal or professional relationships, affiliations, knowledge or beliefs) in the subject matter or materials discussed in this manuscript. The authors declare no conflict of interest".

\section{AUTHOR CONTRIBUTIONS}

$\mathrm{KH}$ conceived the ideas and experimental design of the study. KH and NK performed experiments / data collection. Data analysis and interpretation. primary author is $\mathrm{KH}$ (wrote most of the paper or drafted the paper). K.H and N.K had approved the final version.

\section{REFERENCES}

[1] I. Radu, "Augmented reality in education: a meta-review and cross-media analysis," Personal and Ubiquitous Computing, vol. 18, no. 6, pp. 1533-1543, 2014.

[2] V. Khan, K. Nuijten, and N. Deslé, "Pervasive application evaluation within virtual environments," in Proc. PECCS, pp. 261-264, SciTePress, 2011.

[3] S. V. Pemmaraju and I. A. Pirwani, "Good quality virtual realization of unit ball graphs," LNCS, vol. 4698, pp. 311-322, Springer, Heidelberg, 2007.

[4] W. J. Shen, C. J. Zhao, Z. R. Shen, and X. Y. Guo, "Virtual reality technology and its application in agriculture," Research of Agricultural Modernization, vol. 9, 2002.
[5] S. Gauglitz, C. Lee, M. Turk, and T. Höllerer, "Integrating the physical environment into mobile remote collaboration," in Proc. MobileHCI, pp. 241-250, ACM, 2012.

[6] A. Amditis, I. Karaseitanidis, and I. Mantzouranis, "Virtual reality research in Europe: Towards structuring the European research area," Product Engineering, 2008.

[7] T. Andersen, G. Anisimovaite et al., "A preliminary study of users' experiences of meditation in virtual reality," 2017 IEEE Virtual Reality (VR), pp. 343-344, 2017.

[8] A. M. Ojeda-Castro, P. Murray-Finley, and J. Sánchez-Villafañe, "Learning management system use to increase mathematics knowledge and skills," Int. J. Technol. Human Interact, pp. 89-100, 2017.

[9] N. Bostrom and E. Yudkowsky, "The ethics of artificial intelligence," Cambridge Handbook of Artificial Intelligence, pp. 316-334, Cambridge, UK: Cambridge University Press, 2011.

[10] L. Botrel, E. M. Holz, and A. Kübler, "Brain painting V2: Evaluation of P300-based brain-computer interface for creative expression by an end-user following the user-centered design," Brain-Computer Interfaces, vol. 2, no. 2-3, pp. 1-15, 2015.

[11] X. Chen et al., "High-speed spelling with a noninvasive brain-computer interface," in Proc. the National Academy of Sciences, vol. 112, no. 44, 2015.

[12] R. Mayer et al., "Clickers in the classroom: Fostering learning with questioning methods in large lecture classes," Contemp. Educ. Psychol., vol. 34, no. 4, pp. 51-57, 2009.

[13] G. Mothibi, "A meta-analysis of the relationship between e-learning and students' academic achievement in higher education," Journal of Education and Practice, vol. 6, no. 9, pp. 6-9, 2015.

[14] N. Islam et al., "E-learning challenges faced by academics in higher education: A literature review," Journal of Education and Training Studies, vol. 3, no. 5, pp. 102-112, 2015.

[15] S.-K. Jirasak, "Developing of indicators of an e-learning benchmarking model for higher education institutions," Turkish Online Journal of Educational Technology - TOJET, vol. 13, no. 2, pp. 35-43, 2014.

[16] Y. Baomin, "The application of distributed VR environment in composes campaign body exercise simulating," Computer Simulation, vol. 14, no. 4, pp. 17-201, 1997.

[17] J. Schild et al., "Altering gameplay behavior using stereoscopic 3D vision-based video game design," in Proc. SIGCHI Conference on Human Factors in Computing Systems ACM, 2014.

[18] W. J. Shen et al., "Virtual reality technology and its application in agriculture," Research of Agricultural Modernization, vol. 9, 2002.

[19] K. S. Feiner, "Augmented reality: A new way of seeing," Scientific American, vol. 286, no. 4, 2002, pp. 48-55.

[20] P. Hämäläinen, J. Marshall, R. Kajastila, R. Byrne, and F. Mueller, "Utilizing gravity in movement-based games and play," in Proc. of the 2015 Annual Symposium on Computer-Human Interaction in Play (CHI PLAY '15), 2015, ACM, New York, NY, USA, pp. 67-77.

[21] A. Çamc1, K. Lee, C. J. Roberts, and A. G. Forbes, "INVISO: A cross-platform user interface for creating virtual sonic environments," in Proc. the 30th Annual ACM Symposium on User Interface Software and Technology (UIST '17), 2017, ACM, New York, NY, USA, pp. 507-518.

Copyright (C) 2020 by the authors. This is an open access article distributed under the Creative Commons Attribution License which permits unrestricted use, distribution, and reproduction in any medium, provided the original work is properly cited (CC BY 4.0).

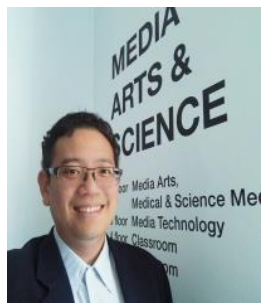

Kongkiat Hirankerd was born in Bangkok, Thailand, on April 13, 1978. Dr. Kongkiat was graduated bachelor's degree (2002) and master's degree (2004) in computer engineering from Eastern Asia University (Thailand) and doctorate degree (2012) from Chulalongkorn University (Thailand).

He currently works as a professor in Rajamangala University of Technology Rattanakosin. He has published books and journals such as books on the development of AR-VR in Thailand and has been published as Adaptive 3D Dress for Augmented Reality for Virtual Dressing Room, 360 Image-Video Virtual Reality Management on Cloud for Big Data, and Adaptive 3D Animation Augmented Reality Models on Game Card with Artificial Intelligent System (THAILAND, Rajamangala University of Technology Rattanakosin, 2019).

Dr. Hirankerd has been vice president of the Thai e-Learning Association and the director of the OpenAR Laboratory since 2018. 


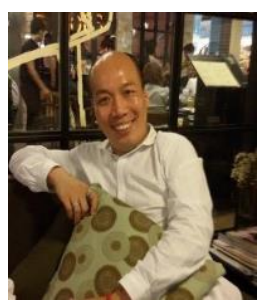

Nattapakal Kittisunthonphisarn was born in Bangkok on October 22, 1973. He holds a bachelor of industrial education in educational technology from King Mongkut's University of Technology Thonburi (KMUTT), Bangkok in 1995. master of education in audiovisual education from Chulalongkorn University, Bangkok in 1998 master of art in advertising from Siam University, Bangkok in 1998 and doctor of educational technology from Ramkhamheang University, Bangkok in 2006.

$\mathrm{He}$ is a lecturer at a Program of Digital Media Design, Faculty of Architecture \& Design, Rajamangala University of Technology
Rattanakosin, NakhonPrathom, Thailand. He worked as a lecturer at department of mass communication technology (2008-2010), Head of Advertising and public relation technology (2010-2012). He is an author of Principle in Advertising Design (2015). He is doing a research which interested in teaching through distance education in rural areas by ICT technologies, need to develop rural education through ICT, E-learning for Supporting Teachers.

Assistant Professor Dr. Kittisunthonphisarn is a membership of E-learning Association Thailand. 